\title{
The Effect of Bone Marrow Derived Mesenchymal Stem Cells on the Survival of Random Skin Flap on Sterptozotocin-Induced Diabetic Rats
}

\author{
Khadijah Rezazadeh $^{1}$ (iD), Farzaneh Chehelcheraghi ${ }^{2 *}$, Khatereh Anbari ${ }^{3}$ (iD \\ 1. Student Research Committee, Faculty of Medicine, Lorestan University of Medical Sciences, Khorramabad, Iran \\ 2. Dept. of Anatomical Sciences, Faculty of Medicine, Lorestan University of Medical Sciences, Khorramabad, Iran \\ 3. Dept. of Social Medicine, Faculty of Medicine, Lorestan University of Medical Sciences, Khorramabad, Iran
}

\begin{tabular}{|c|c|}
\hline Article Info & ABSTRACT \\
\hline doi 10.30699/jambs.26.119.24 & $\begin{array}{l}\text { Background \& Objective: Wound dressing and healing in diabetic patients is } \\
\text { encountered with many problems. This study aimed to investigate the effect of bone }\end{array}$ \\
\hline $\begin{array}{l}\text { Received: 2018/06/26; } \\
\text { Accepted: 2018/11/28; }\end{array}$ & $\begin{array}{l}\text { marrow derived mesenchymal stem cells (BM-MSCs) on the survival of random skin } \\
\text { flap (RSF) on Streptozotocin-induced diabetic rats (STZ) using an optical microscope. }\end{array}$ \\
\hline Published Online: 01 Nov 2018; & Materials \& Methods: In this study, 60 male Albino Wistar rats were used (average \\
\hline $\begin{array}{l}\text { Use your device to scan and read the } \\
\text { article online }\end{array}$ & $\begin{array}{l}\text { Health-Cells (HC), 3) Health-Sham (HS), 4) Diabetic-Non (DN) that were became } \\
\text { diabetic by injecting STZ } 70 \mathrm{mg} / \mathrm{kg} \text { intraperitoneally), 5) Diabetic-Sham (DS), and 6) } \\
\text { Diabetic-Cell (DC). In all groups, the day of surgery was considered as the zero day, on } \\
\text { the back area of animal, the flap was created with a size of } 8 \times 3 \mathrm{~cm} \text { and the BM-MSCs } \\
\text { were performed. The sampling was performed on day } 7 \text { after surgery from the region } \\
\text { where Transitional Zone (TZ) necrosis was initiated. }\end{array}$ \\
\hline Corresponding Information: & $\begin{array}{l}\text { Results: BM-MSCs increased the number of blood vessels }(P=0.009) \text { and the } \\
\text { histology parameters (wound demarcation } P=0.0001 \text {, granulation tissue } P=0.0001 \text { ) } \\
\text { significantly compared to the control group. But this increase was not significant in } \\
\text { the area of the survival region. }\end{array}$ \\
\hline \multirow{2}{*}{$\begin{array}{l}\text { Corresponding Information: } \\
\text { Farzaneh Chehelcheraghi, Dept. of } \\
\text { Anatomical Sciences, Faculty of Medicine, } \\
\text { Lorestan University of Medical Sciences, } \\
\text { Khorramabad, Iran } \\
\text { Email: fr.chehelcheraghi@gmail.com }\end{array}$} & $\begin{array}{l}\text { Conclusion: It was concluded that after treatment with BM-MSCs, the wound } \\
\text { healing process in both non-diabetic and diabetic groups was increased in accordance } \\
\text { with histological characteristics. }\end{array}$ \\
\hline & $\begin{array}{l}\text { Keywords: Diabetes mellitus, Random skin flap, Bone marrow, Stem cells, } \\
\text { Streptozotocin, Survival }\end{array}$ \\
\hline (c) $\underset{\mathrm{OY}}{(1)(9)}$ & $\begin{array}{l}\text { so of the Creative Commons Attribution-noncommercial } 4.0 \text { International License which pern } \\
\text { ation. }\end{array}$ \\
\hline
\end{tabular}

\section{Introduction}

Diabetes mellitus is a metabolic disease that causes delayed ulcer and infection against the disease. Cutaneous wound healing is a dynamic process aiming to repair the skin integrity. Cell proliferation, migration, and differentiation are the results of changes in gene expression and phenotype, inflammatory cells, endothelial cells, fibroblasts and keratinocytes in damaged skins. Cytokines and growth factors are significantly involved in creating and controlling the stages of wound healing. These signaling peptides are produced by various cells resulting in consistent efforts for restoring the function of skin (1). Skin flaps are mostly used in all areas of plastic surgery, especially in restorations necrosis and ischemia. After removing the skin lesions and tumors, flaps are often the only suitable option for surgical repairs. Flaps have been used for centuries, and during this period, surgical and systemic techniques have been developed to increase the survival area of skin flap (2). Skin flap surgery under diabetes conditions is associated with several and difficult pathophysiology problems. Currently, there is not any accepted strategies for the treatment of flap necrosis. Diabetes exacerbates flap necrosis and generally causes the increase in the oxidative stress of the tissue. New potential treatments for improving the survival of the flap and for suppressing the necrosis and oxidative stress have been investigated $(2,3)$. In diabetic patients, protein synthesis decreases, while catabolism increases, and as the growth of tissues changes, their reconstruction and restoration would change. Necrosis is the most common complication after restoration of the flap. Sufficient blood flow $(4,5)$ is the most important aspect that determines the survival of the skin flap. But incomplete or complete skin flap necrosis is one of the common problems with this type of surgery. Indeed, necrosis is caused by postoperative ischemic injuries (5). Management of necrosis treatment is usually time consuming and it needs using multiple wound dressing or multiple surgeries $(6,7)$. Considering the high and increasing prevalence of diabetes in the world and the fact that involvement of patients with the wounds is becoming chronic, the importance regarding the 
investigation on this issue becomes highlighted. However, many efforts have been made to overcome the necrosis of various types of ulcers by modern and safe treatment methods, but no fixed clinical treatment has been identified yet (8-10). Angiogenesis, as a delay mechanism in the wound healing process, causes recovery along with an increase in the number of blood vessels, which itself increases the perfusion in the flap (11). There are several strategies for reducing the healing process of wounds, including the presence of stem cells and growth factors that improve the healing process, significant growth factors in terms of the regeneration process include: the Transforming Growth Factor (TGF), Vessels Endothelial Growth Factor (VEGF), Platelet-Derived Growth Factor (PDGF), basic Fibroblast Growth Factor (b FGF), and Endothelial Growth Factor (EGF)(12). Bone Marrow Mesenchymal Stem Cells (BM-MSCs) improve the regeneration process of skin wounds specifically, due to its excellent ductility and the ability to secrete growth factors, they are used as a good source of cell therapy in most clinical models (13). The BM-MSC transplant improves the regeneration process of diabetic ulcers in rats (14). The use of stem cells is among the new treatments for improving the survival of the flap caused through angiogenesis and necrosis suppression. Numerous empirical and clinical studies have shown that, bone marrow mesenchymal stem cells have a very high potential among cellular sources, and their transplantation in wound results in angiogenesis, and improvement of the wound healing process. The effect of mesenchymal stem cells on improving the regeneration process of chronic and diabetic wounds is accomplished through several mechanisms; these mechanisms include reducing the inflammation of the tissue, inducing angiogenesis in the wound and reducing scar formation after wound healing process $(7,12,13)$.

Despite a large number of clinical studies conducted on comparing different methods of regeneration in diabetes mellitus, experiments and studies on the therapeutic effects of BM-MSCs on necrosis are limited. In this study, our aim was to investigate the effect of stem cells on the survival of flap in an experimental model of random skin flap in non-diabetic (control group) and STZ diabetic rats by measuring the area of the survival region and histopathologic evaluation.

\section{Materials and Methods}

\section{MSC Isolation, Expansion, and Labeling}

In order to extract MSC, left thighbone of rats (250$250 \mathrm{~g}$ ) was selected randomly a mixture of ketamine (50 $\mathrm{mg} / \mathrm{kg})$ and xylazine $(5 \mathrm{mg} / \mathrm{kg})$ was applied to anesthetize the rats intraperitoneally. Following the disinfection of the site, surgical instruments were applied for collecting the bone marrow contents from the bone marrow cavity using a 5-cc syringe and an $18 \mathrm{G}$ needle. After centrifuging the bone marrow-derived cells in growth medium (DMEM), it was suspended and then was separated using Ficoll-Paque Density gradient (15). Flow cytometry provided by the Iranian Biological
Resource Center was used to confirm the surface markers of cell expression such as CD90, CD45, CD105, and CD34 in the third sub-culture. Red fluorescence CM-Dil was applied to label the cells. For preparing the cell labeling solution, CM-Dil was diluted with ethanol $95 \%$, at a concentration of $20 \mathrm{~g} / \mathrm{mL}$, and cells were selected with the density of $1 \times 10^{6}$ in $1 \mathrm{~mL}$ DMEM. Then, $5 \mu \mathrm{L}$ of the cell labeling solution was added to each $1 \mathrm{~mL}$ of cell suspension and was mixed with gentle pipetting; next, incubation was done for 20-1 minutes at $37^{\circ} \mathrm{C}$, and then the falcon in which the cells were suspended was placed along with CM-Dil for centrifuging at a speed $1500 \mathrm{rpm}$ for 5 minutes, preferably at $37^{\circ} \mathrm{C}$. Ultimately, after discarding the supernatant, the cells were suspended gently in a warm environment $\left(37^{\circ} \mathrm{C}\right)$ once more in the DMEM (16). Trypan Blue staining was applied for distinguishing live and non-living cells for determining the percentage of live cells. Briefly, normal saline was used to dilute cell samples. Trypan Blue was mixed with cell suspension, and after suitable pipetting, $10 \mu \mathrm{L}$ of solution was loaded on a hemocytometer slide. Following the incubation at room temperature, counting the cells was done under a microscope in all four hemocytometer squares and the number of cells per square $(106 \mathrm{~g} / \mathrm{mL})$ was specified $(8)$.

\section{Animal Study}

This work was authorized by the Ethics Committee of Lorestan University of Medical Sciences (LUMS. REC.1395.200). Sixty adult male Albino Wistar rats were used, weighting -250-300 g in this study. Animals were divided randomly into two groups: diabetic (D) and healthy $(\mathrm{H})$, and each group was divided into three subgroups: Health-Non group (Control) (HN): Without saline and cell injection, Health-Saline (Sham) group (HS): $0.5 \mathrm{~mL}$ Saline, Health-BMMSCs group (HC): with cell injection, the Diabetic-Non group (Control) (DN): without BMMSCs and saline injections, the Diabetic-Saline group (Sham) (DS): receiving $0.5 \mathrm{~mL}$ of saline, Diabetic-BMMSCs group (DB): with injection of BMMSCs. Rats of diabetic group received Sterptozotocin solution $70 \mathrm{mg} / \mathrm{kg}$ (Sigma-Aldrich, St Louis, MO, USA) diluted in sodium citrate buffer $50 \mathrm{mM}$ $(\mathrm{pH}=4.5)$ intraperitoneally and with a dose of $70 \mathrm{mg} / \mathrm{kg}$, for diabetes type 1 induction. Then Blood glucose samples from the animal's veins were measured by a glucometer on day 3 after STZ injection. Also, for one month, the rats were kept under the diabetes type 1 model and their blood glucose was measured twice again by a glucometer, so the blood glucose of diabetic rats was measured three times. Those rats were considered as diabetes type 1 models and were studied after 8-hour fasting which their blood glucose level was about 250 $300-\mathrm{mg} / \mathrm{dl}$ with Polydipsia and Polyuria clinical symptoms $(17,18)$. After 4 weeks, all animals had general anesthesia with Ketamine $(100 \mathrm{mg} / \mathrm{kg}$, IP; Sigma-Aldrich, St. I. Louis, Mo) and Xylazine $(10 \mathrm{mg} / \mathrm{kg}$, IP; Sigma-Aldrich, St. I. Louis, Mo). The area on the back of animals was shaved and the rectangle shaped flap was created in a size of 30x80 mm. In this flap model, the entire thickness of the skin and skin 
muscle (Panniculus carnosus) was removed. BMMSCs that were stained with CM-DiI (Invitrogen ${ }^{\mathrm{TM}} \mathrm{C} 7000$ ) red fluorescence color were homogeneous in experimental groups containing $7 \times 10^{7}$ in $0.5 \mathrm{~mL}$ DMEM and transplanted in 12 equal positions on the left and right bed of the flap from the distal to the proximal (flap base). The control group received saline at the same volume of BMMSCs and CEE. Then, the raised section of the flap was restored and was stitched using nylon yarn $0.4 \%$. The day of the surgery was considered as zero day (19).

\section{Survival Area Analysis}

All animals were studied and compared considering flap tolerance and treatments, and cases such as acute inflammation, abscess formation, serum aggregation or necrosis were investigated usually within 7 days after skin flap surgery. Survival areas that could be separated from the necrosis area were those without any change in color and stiffness. Then digital images were taken by the Sony Jap camera (SONY) from each flap, and the survival area of flap was analyzed by Image $\mathbf{J}(\mathrm{NH}$. USA) and also the images were evaluated by the Adobe Photoshop es5 in terms of survival area, and the percentage of the flap survival area was investigated and compared by Adobe system In Scan (20).

\section{Preparation and Processing of Tissue}

On the 7th day after the operation, the texture of flap was evaluated using microscopic study. First, the cotton was imbued with Chloroform solution and was placed in a closed glass container and the animal was placed in it. After a few minutes, the animal was anesthetized deeply and they looked dead, so its hands and feet were attached to the surgical bed by a special yarn, in a position that the animal was laid on its abdomen. In this way, the flap was completely exposed. Then, sample was procured from the Transitional Zone (TZ), as the initiation region of necrosis, and was kept in fixative solution (formalin $10 \%$ ) at normal room temperature. And after one week, $1 \mathrm{~mm}$ of tissue pieces were placed in paraffin blocks, and slides were provided with a thickness of $5 \mu \mathrm{m}$ from these blocks and were stained with Hematoxylin-Eosin (H\&E). All histological studies were calculated using Histomorphometry methods. In this method, histological observations were performed on the linear focusing of $1033.3 \mathrm{~mm}^{2}$ in a transverse line from the flap area, with a magnification of $\times 100$ (21).

\section{Microscopic Fluorescence}

On day 7 after surgery, $H \& E$ stained slides were assessed by fluorescent microscope with red filter regarding the presence of CM-DiI positive cells in the epidermis, muscle, and dermis of flap tissue (22).

\section{Volume Density of the Vessels}

The number of blood vessel densities is calculated based on stereological methods, which reports 3Drelated information in terms of three-dimensional values. The framework of a field is arranged by a unique counting frame in the dermal area.

Volume Density of the vessels from $V_{v}$ (vessel /dermis) was counted as $\mathrm{P}$ (Vessel) $/ \mathrm{P}_{\text {(dermis), where the }}$ number of $\mathrm{P}_{\text {(Vessel) }}$ was placed between the points of the pattern $(17,23)$

\section{Wound Demarcation and Granulation Tissue Analysis}

The tissue Granulation grading was scored as: Granulation tissue $=1$, Granulation tissue partially unhealthy $=2$, Granulation tissue healthy but not fully even with epidermis $=3$ and Granulation tissue healthy, which evens up wound depth=4. For the purpose of expressing the Wound demarcation grading, the scoring obtained by Wound tissue area was marked distinctly from healthy tissue $=1$, Wound tissue healthy but immature and easily distinguished $=2$ and Wound tissue well integrated into normal tissue $=3(24,25)$.

\section{Statistical Analysis}

Statistical analysis was conducted using SPSS 19 (SPSS Inc., Chicago, Ill. USA). Mann-Whitney and Kruskal-Wallis nonparametric tests were used to determine the probability of significant differences for independent samples, because data were not distributed normally on statistical valuation. A P-value $<0.05$ was considered to be statistically significant and the results are expressed as Mean \pm SD

\section{Results}

All animals that had STZ injections showed high and steady hyperglycemia during the study. Five days after STZ injection, the mean glucose level in the treatment groups was equal to $468.3 \pm 62.3$ and was equal to $425.4 \pm 51.2$ in the control groups, and one day before the surgery, mean Serum glucose was equal to $714.3 \pm 16.2$ in the treatment groups and was equal to $731 \pm 27.1$ in the control group. Statistically there was no significant difference between the two stages of blood sampling between the treatment and the control groups.

\section{MSC Specification by Flow Cytometry}

Using flow cytometry, the surface markers of low expression of CD45 and CD34, and high expression of CD90 and CD105was obtained, along with isotopic control, the cells were confirmed to be mesenchymal and stem cell (Figure 1). 

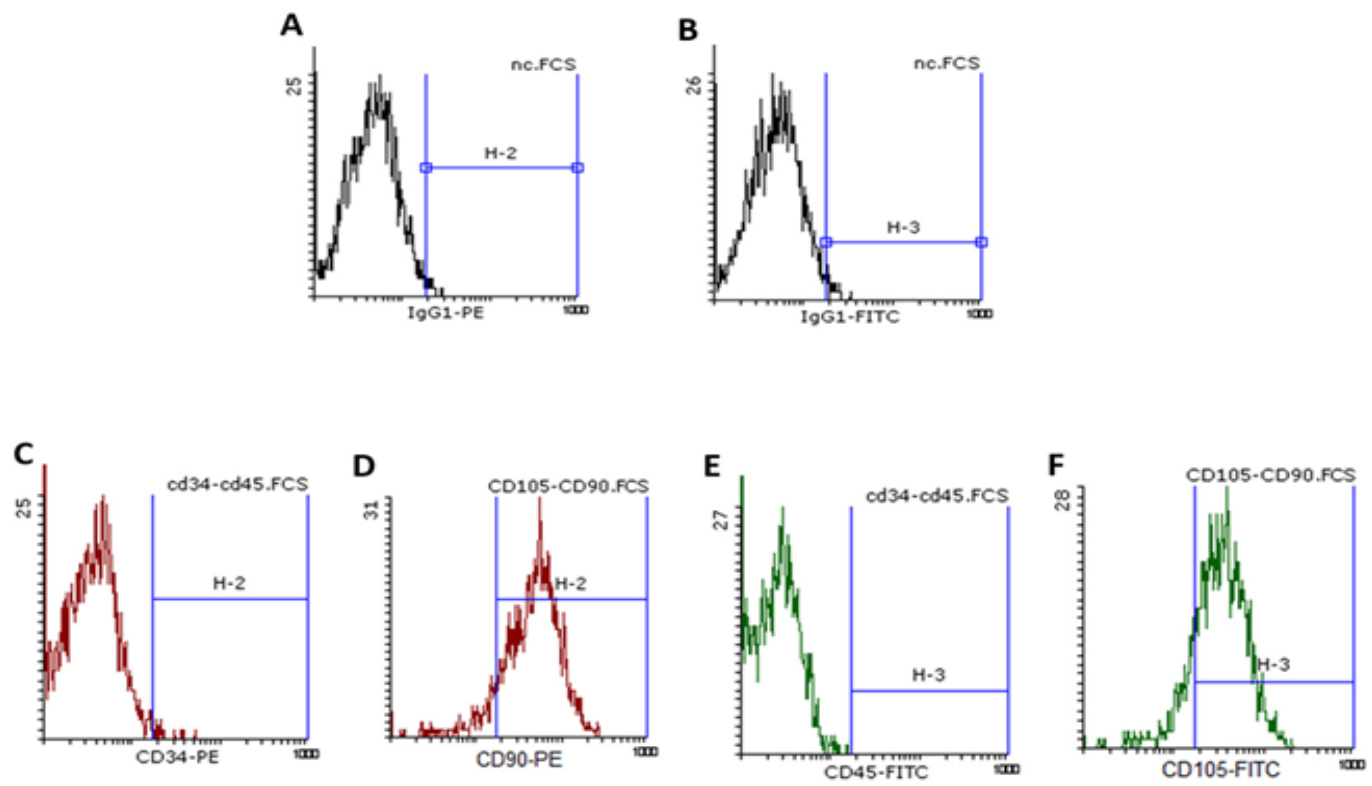

Figure 1. Bone marrow mesenchymal stem cell Immunophenotypes: In vitro expanded mesenchymal stem cells were put to analysis by flow cytometry regarding CD45, CD34, CD90, and CD105 biomarkers expression. A and B graphs display negative isotope controls for the mentioned biomarkers, in the respective order. $\mathrm{C}, \mathrm{D}, \mathrm{E}, \mathrm{F}$ graphs display stem cell sample for each biomarker. Cells within the D and F region of the histogram were high expression of CD90 and CD105. Cells within the $D$ and $F$ region of the histogram were the low expression of CD34 and CD45.

\section{Survival Area Rate}

Based on the results of One-way Analysis of Variance (ANOVA), the mean area of the wounds on 0 day of surgery was equal to $91.51 \pm 26.63$ that no statistically significant difference was observed in the studied groups. But, according to the results of the $t$-test, the difference was statistically significant $(P=0.012)$ in terms of the percentage of healthy levels on the 7 th day after surgery, between the diabetic cell recipient group
$(77.4 \pm 11.7 \%)$ and the healthy cell recipients (59.71 $\pm 74 \%)$. And comparing diabetic rats receiving cell with the control groups, the difference was significant $(60.3 \pm 19.5 \%, P=0.08)$. But, comparing this group with Sham, the difference was not significant $(P=0.207,67 \pm 16.2 \%)$, as well as in healthy rats receiving cell compared to control groups $(P=0.872$, $60.7 \pm 14.6 \%)$ and with Sham $(0.698,57.9 \pm 9.35 \%)$ (Figure2).

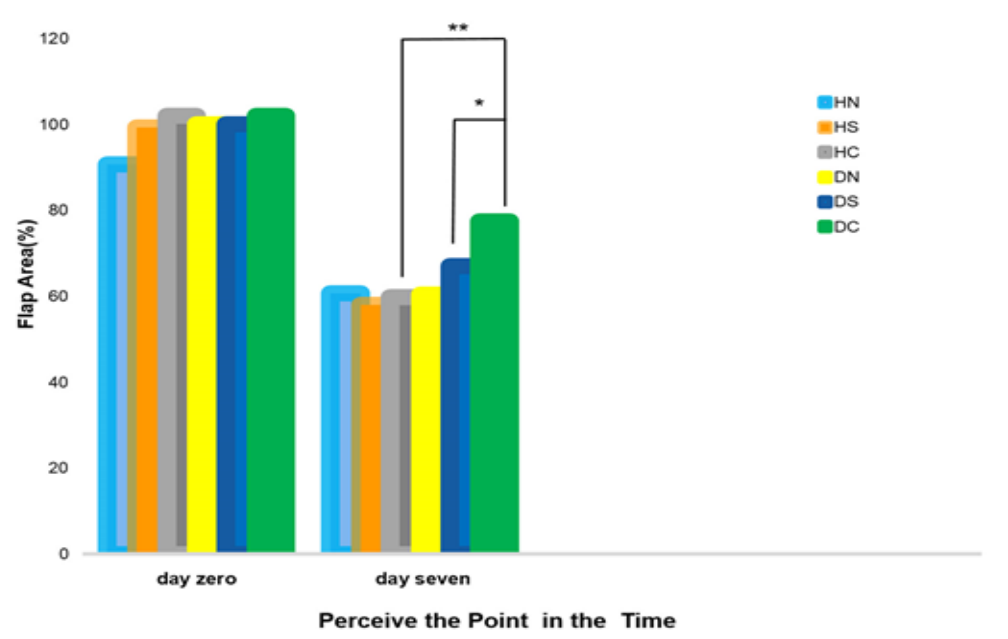

Figure 2. Graph for showing areas of flap size on day zero and flap survival areas on seventh day. Treatment with BMMSCs increased the level of survival in day 7 in diabetic group $(P<0.01=* *, P<0.05)$.

\section{Fluorescent Microscope}

On the $7^{\text {th }}$ day after surgery, CM-DiI-labeled BMMSCs were detected by fluorescent microscope in the flap tissue in epidermis, dermis and in muscle layer (Figure 3). 


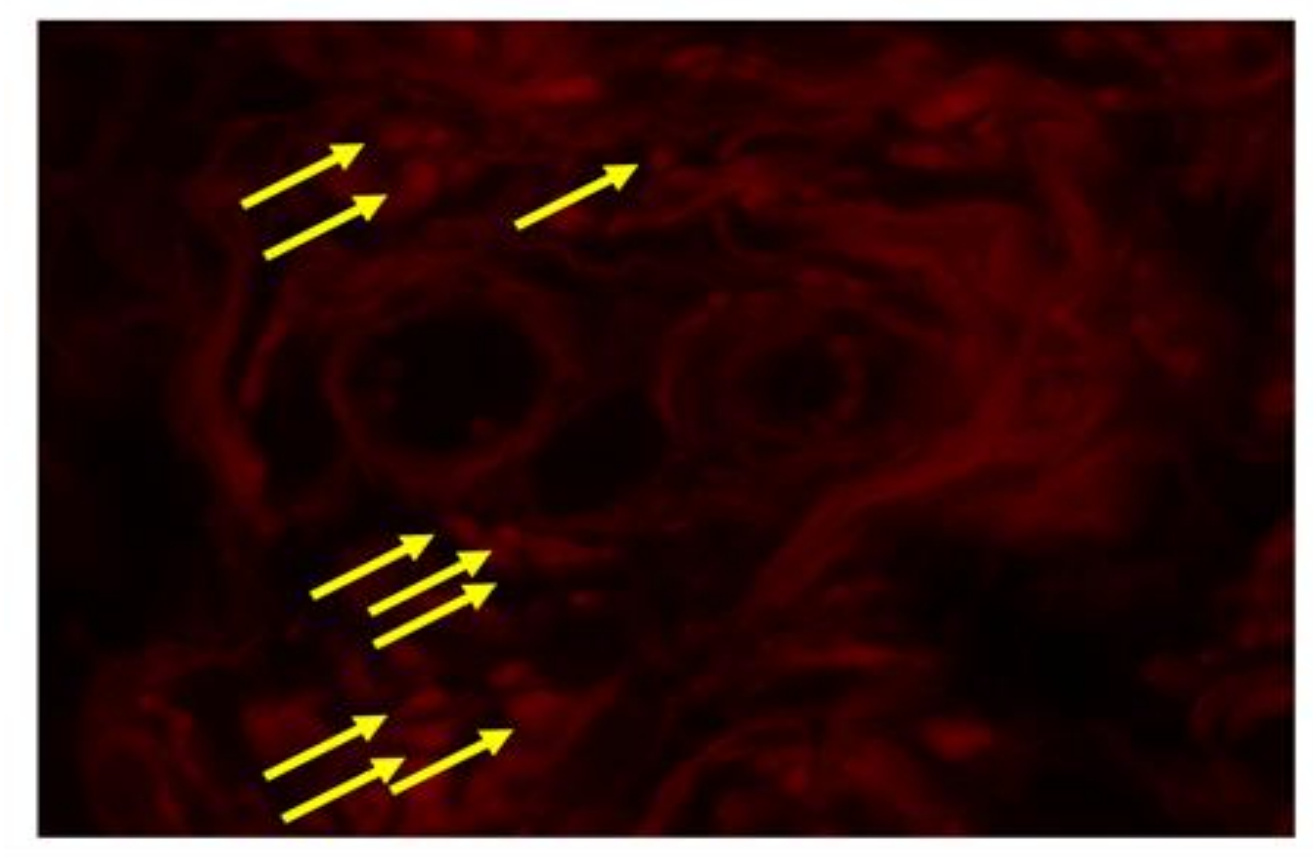

Figure 3. Detection of transplanted DiI-labeled BMMSCs. DiI-positive cells (red color) arranged near the vessels. (Magnification by $\times \mathbf{4 0 0}$ ).

\section{Histomorphometry Parameters}

Based on the results obtained by Kruskal-Wallis test, we found that the number of blood vessels in the Diabetic+Non (control), Diabetic+BMMSCs, Diabetic+Saline groups $(P=0.0001)$ was significantly higher than the control group, and in the Health+Non (Control), Health +BMMSCs, Health+Saline groups $(P=0.849)$ was not significantly higher than the control group. Also considering the number of vessels, in two-by-two comparison there was difference $(P=0.0001)$ (Figure 4B) between the diabetic rats receiving the cell and the healthy rats receiving the cell. Based on the results of Kruska-Wallis test, the difference in mean values was statistically significant: tissue granulation $(P<0.0001)$ and demarcation of wound was also significant $(P<0.0001)$, in Diabetic+None (control), Diabetic+BMMSCs, Diabetic +Saline and in Health+Non (Control), Health +BMMSCs, Health+ Saline, as well. Also, two-by-two comparison of histologic changes was performed between Health+ BMMSCs and Diabetic+BMMSCs. Based on the results of the mentioned table, the difference in tissue granulation $(P=0.004)$ and wound demarcation $(P=0.022)$ were statistically significant between the two mentioned groups based on the results of Mann-Whitney test (Table1, Figures 5 and 6).

Table 1. Intergroup comparison of biopsy samples for Granulation tissue and Wound demarcation.

\begin{tabular}{cccccc} 
& Groups & $\mathbf{n}$ & Mean & Standard deviation & $P$ \\
\hline Granulation & HN & 10 & 2.75 & 0.21 \\
tissue (Score) & HS & 10 & 2.17 & 0.40 \\
& HC & 10 & 2.07 & 0.16 & 0.004 \\
& DS & 10 & 3.04 & 0.42 & 0.29 \\
Wound & DC & 10 & 2.21 & 0.31 \\
(Score) & HN & 10 & 2.31 & 0.10 \\
\hline
\end{tabular}



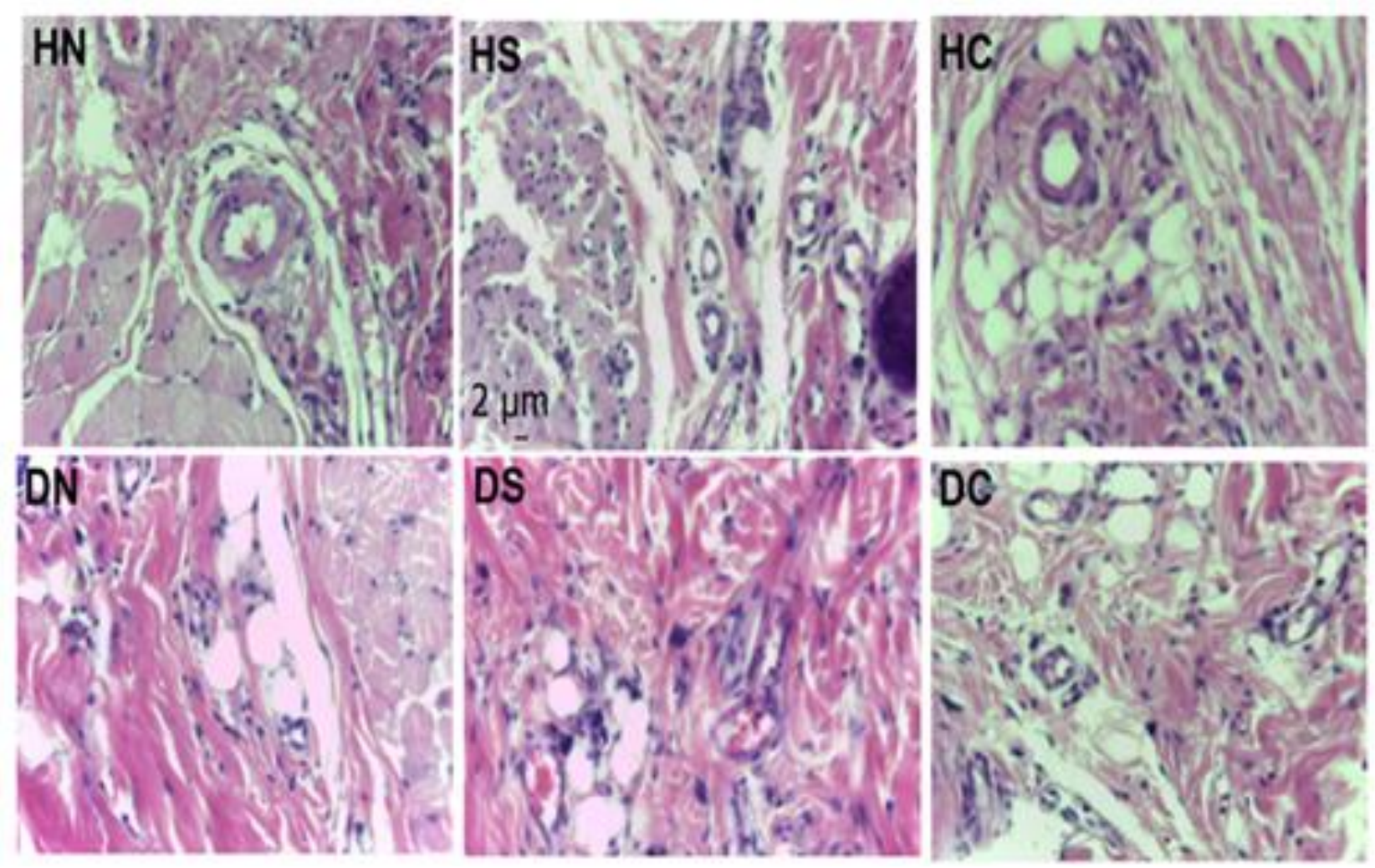

B

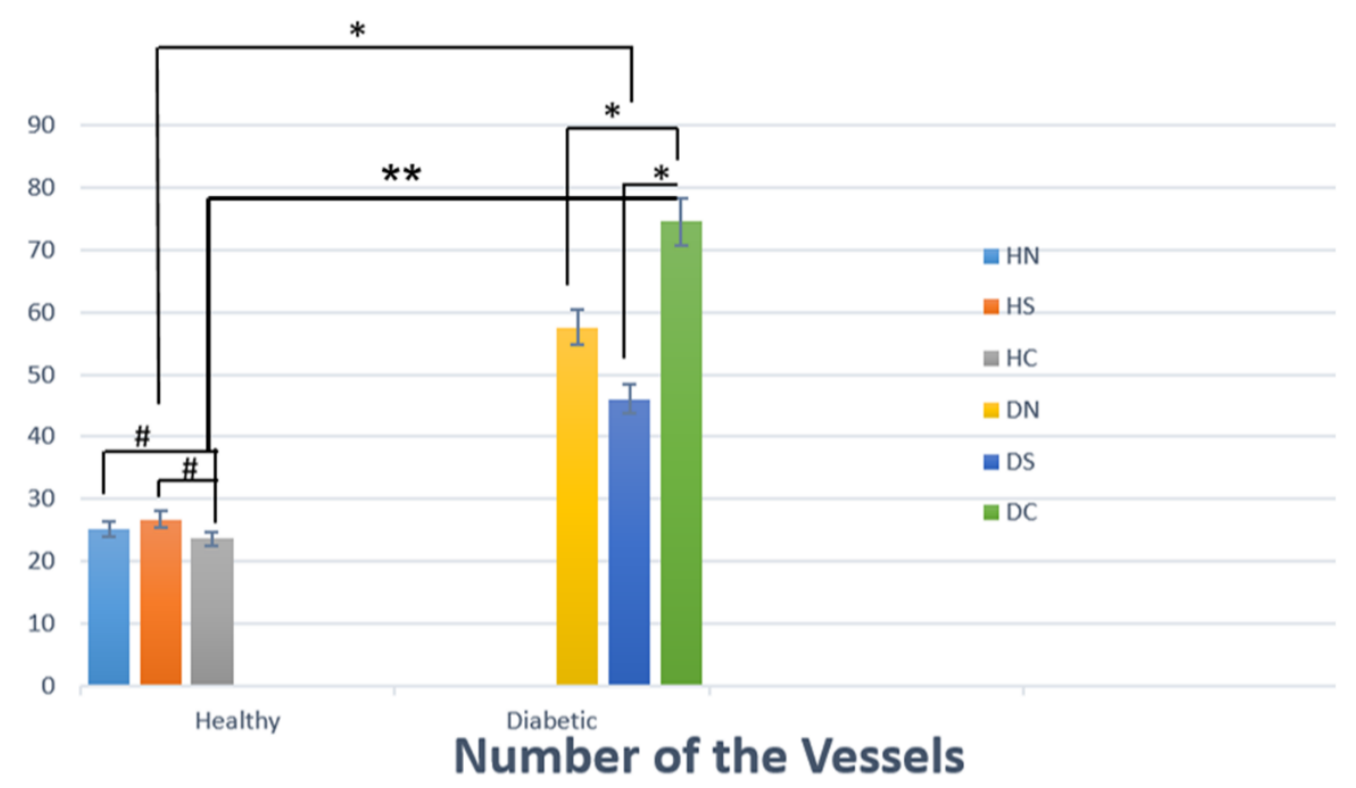

Figure 4. A, shows the vascular distribution on the cross-section of flap tissues in the 6 groups. H\&E staining, original magnification by $\times 40$, scale $b a r=2 \mu \mathrm{m}$. $B$, the number of blood vessels increased in BMMSCs receiving groups. $B$, Statistical analysis was significant in the diabetic and natural group $(* P \leq 0.05, * * P<0.0001 \# P>0.05)$. 
A
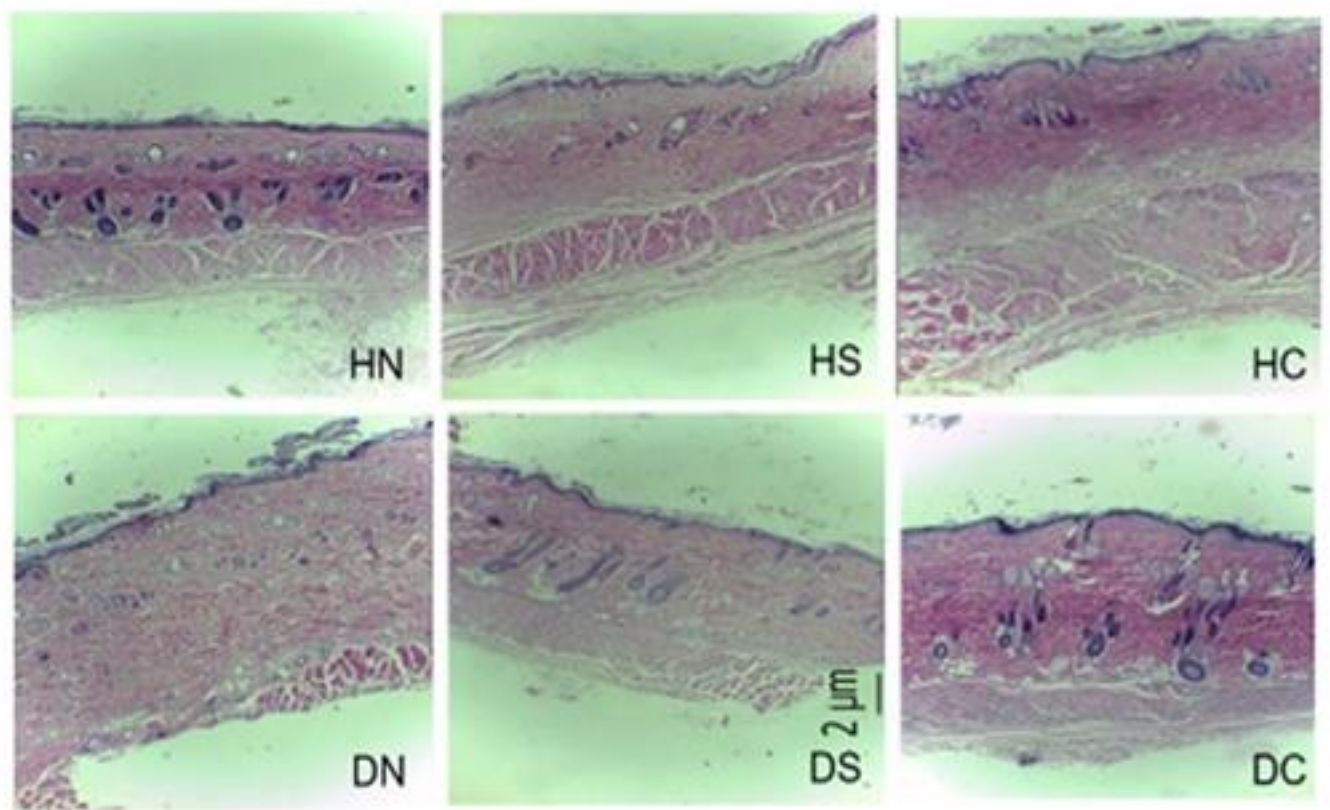

B

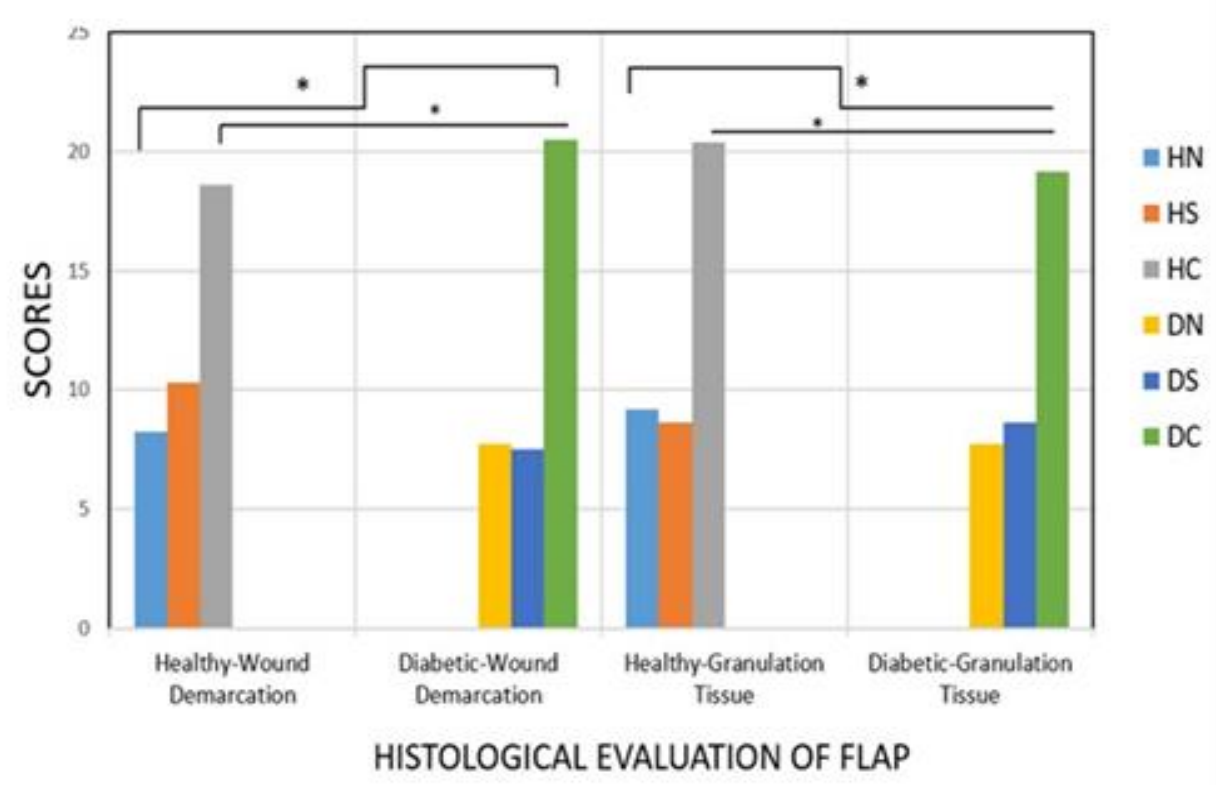

Figure 5. A, light microscopic images of dorsal skin flap: (HN) Intact control group, (HS) Sham operated group, (HC) BMMSCs group, (DN) Diabetic control group, (DS) Diabetic Sham operated group, (DC) Diabetic BMMSCs group. H\&E staining, original magnification by $\times 10$, scale bar $=2 \mu \mathrm{m}$. B, diagram of the granulation tissue and wound demarcation scores. All values are expressed as means \pm standard deviations (SDs). $N=10$ per group. ${ }^{*} P \leq 0.05$

\section{Discussion}

In the present study, inducing diabetes type 1 in the animals was performed through Sterptozotocin-induced, on day 0 by creating an RSF model, along with adding cell (BMG-MSCs), we evaluated survival and histopathologic of the skin flap on the seventh day after surgery. The results emphasized the increase in the survival rate of flap in diabetic rats, more than nondiabetic rats.
Chronic wounds are common illnesses and they heal hard. The greatest treatments accessible can only succeed by $50 \%$ in terms of wound closure which is often transitory. Implantation of BM-MSCs improved wound healing however, the strategies included have not been approved wholly (26). The present study showed that BM-MSCs have the wound healing ability in diabetic rats. We have demonstrated the presence of BM-MSCs in both regions of dermis, epidermis and flap tissue vessels by 
fluorescent electronic microscope. Healing of wounds is contained migration of keratinocytes, fibroblasts and endothelial cells to the wound bed organized with proper ECM molecule deposition and proliferation of these cells (27). Histopathologic study and scores showed a significant difference in the recovery process score in the cell-receiving groups compared to other groups. A study found that Implantation of BM-MSCs was found to improve wound healing in normal and diabetic mice accompanying with improved angiogenesis. Though, BM-MSCs which were close to the vasculature were found but not in the vascular walls, signifying a paracrine effect of BM-MSCs in angiogenesis and wound healing (26). Also, in our study, flaps were detected in Diabetic+ BM-MSCs groups with significantly increased in terms of micro vascular density.

Appropriate circulation for correcting tissue ischemia is one of the essential situations for wound healing. Neoangiogenesis causes raised oxygen levels and progressed collagen synthesis and cell proliferation (5). In the present study, we determined, there was a significant increase in the number of vascular segments in the diabetic+BM-MSCs, Health+BM-MSCs groups. New Research found that histopathological results, regarding the special effects of sericin on wound healing investigated by using a dorsal skin flap model, the sign of the Sericin group was similar to the intact control group in terms of collagen distribution, scar formation, but collagen discoloration was changed (25). In our study, BM-MSCs reduced demarcation of wounds significantly in diabetic and non-diabetic groups compared to control groups, reducing wound demarcation itself increased reepithelialization with prominent effects on inflammatory secretions and fibroblastic activity.

Studies on diabetic wounds in human and animal models have shown that, there are very vast changes in the molecular level that cause delay in the wound healing process (24). In wounds of diabetic patients, the decrease in the formation of granulation tissue, and the decrease in the blood flow and also the increase in the blood viscosity occur that ultimately lead to defect in the angiogenesis, which is one of the most important difficulties regarding the challenge of wound healing process. Therefore, cell therapy by the help of stem cells to produce growth factors and angiogenesis stimulation is a novel treatment method and choice of many scholars (18). The increase in the granulation tissue is accompanied by the increase in the vascular sprouts and the spread of Microvesseles. BMMSCs are multivalent stem cells that can differentiate into several cell types, including fibroblasts, bone, muscle and cartilage. These cells are capable of producing a variety of cytokines and growth factors (28). Sustenance of the newly formed granulation tissue and the survival of keratinocytes necessitate the formation of new blood vessels. Previously, we found that angiogenesis was improved in wounds receiving implantation of BM-MSCs improved (8). Another study reported that BM-MSC conditioned medium had potent chemo-attractive agent and also mitogenic effects on endothelial cells (26). Due to their high capability to differentiate into other tissues of the BM-MSCs, they are used in skin regeneration treatment, myocardial infarction, and bone defects, etc. After transplantation, BM-MSCs migrate to the wound site and help the recovery of the wound $(28,29)$.

Plastic surgery of all types of flap is one of the most commonly used wound healing remedies. This type of surgery has also many challenges due to post surgery necrosis. Necrosis is the result of a failure occurred in one of the stages of wound healing process. The mechanisms that are exposed to damages during the wound healing process and cause the failure of the healing process include: incomplete migration of the inflammatory cells into the wound site, reduction in the production of growth factors and tissue regeneration (6). Diabetic people with diabetic foot syndrome are encountered with many challenges in repairing these types of wounds through plastic surgery, which are caused by vascular neuropathy and therefore causes problem in the repair process (30). A recent study has investigated the regeneration of wounds by the help of BM-MSCs, restoring the normal skin function and eliminating the redundant skin using adult stem cells, and have achieved favorable results (27). Flap transition is simple technically, and flap color and texture can be accorded to those of the recipient place. However, distal flap necrosis remains as a major problem. In a study, it was revealed that (Oxytocin) OT injection rises the plasma levels of IGF-1 and NGF significantly and develops Musculocutaneous flap survival (31).

I another study that was conducted to evaluate the effect of bone marrow mononuclear cells on improving survival of skin flap, it was shown that transfer of bone marrow derived mononuclear cells could promote new angiogenesis and improve survival of skin flap, and was also emphasized on the use of bone marrow derived mononuclear cells compared to extracted stem cells from fat cells, which is more effective in skin flap survival (22). This study was consistent with the results of our study, obviously only in the flap survival region, and increase in the recipient group, which was only observed but was not significant. In our previous study, conducted in 2015, the beneficial effects of topical use of CEE and BM-MSCs on skin flap survival have been shown, suggesting that the chicken embryo alone or along with the BM-MSCs improves and survives skin flap (8). Injection of different 
types of stem cells with the secretion of Paracrine factors in angiogenesis increases the survival of the skin flap. In a recent study, it was shown that by injection of a human umbilical cord stem cell to diabetic rats three days before the onset of creating a flap and causing a McFarlane model random skin flap, they were able to change the blood flow pattern and to change the area of necrosis, and the survival level of the skin flap was increased ultimately (32). Also, in another study using bone marrow derived stem cells (BMMSCs) along with stromal derived-factor- $1 \alpha$ (SDF- $1 \alpha)$ in wounds of diabetic rats, the wound healing process was improved according to cell-based therapy (CBT), and the molecular effects that accelerated wound healing process were more emphasized (33). In our study, likewise, by the help of BM-MSCs, the number of vascular sections increased. This increase led to an improvement in the survival level of the flap.

Tissue granulation, which is one of the main components of the regeneration process, in the cell receptor groups, had a statistically significant increase. Also, Paracrine effects of BM-MSCs have been emphasized in accelerating the wound healing process, indicating these factors which released from these cells invoke macrophages in the wound and thereby accelerate the wound healing.Studies of BMMSCs suggest that these cells secrete insulin-like growth factor1 (IGF), which is a key factor in the regenerative process, and the IGF1 gene which is expressed at a very high level in mRNA, BM-MSCs (26). In our research, in groups receiving BMMSCs, the wound demarcation and the area of the necrosis tissue were less clear rather than the control groups which these factors were decreased.

\section{Conclusion}

The results of the present study indicated that BMMSCs accelerate the wound healing process in nondiabetic and diabetic rats, which was evaluated histologically, by considering the number of vascular sections and survival level. The results of this study may lead to the presentation of therapeutic approaches in skin flap models concerning diabetes ultimately, and they can be effective in clinical trials. Future research may be able to reduce the psychological effects of skin trauma, duration of hospitalization, and health-care costs.

\section{Acknowledgements}

We thank the Deputy of Research and Technology of Lorestan University of Medical Sciences for financing the project.

\section{Conflict of Interest}

Authors declared no conflict of interests.

\section{References}

1. Böhm D, 1- Kiwanuka E, Junker J, Eriksson E. Harnessing growth factors to influence wound healing. Clin in Plast Surg. 2012; 39(3): 239-48. [DOI:10.1016/j.cps.2012.04.003] [PMID]

2. Bagdas D, Etoz BC, Ozturkoglu SI, et al. Effects of systemic chlorogenic acid on random-pattern dorsal skin flap survival in diabetic rats. Biol Pharmaceut Bullet. 2014; 37(3): 361-70. [DOI:10.1248/bpb.b13-00635] [PMID]

3. Carvalho ENd, Ferreira LM, Carvalho NASd, Abla LEF, Liebano RE. Viability of a random pattern dorsal skin flap, in diabetic rats. Acta Cir Bras. 2005; 20(3): 225-8. [DOI:10.1590/S010286502005000300006]

4. Memarzadeh K, Sheikh R, Blohmé J, Torbrand C, Malmsjö M. Perfusion and oxygenation of random advancement skin flaps depend more on the length and thickness of the flap than on the width to length ratio. Eplasty. 2016; 16: e12.

5. Leng X, Fan Y, Wang $\mathrm{Y}$, et al. Treatment of ischemia-reperfusion injury of the skin flap using human umbilical cord mesenchymal stem cells (hUC-MSCs) transfected with "F-5" gene. Med Sci Monit. 2017; 23: 2751-64. [DOI:10.12659/MSM.905216] [PMID] [PMCID]

6. Rah DK, Min HJ, Kim YW, Cheon YW. Effect of platelet-rich plasma on ischemia-reperfusion injury in a skin flap mouse model. Int J Med Sci. 2017; 14(9): 829-39. [DOI:10.7150/ijms.19573] [PMID] [PMCID]

7. Kim $\mathrm{HJ}, \mathrm{Xu} \mathrm{L}$, Chang KC, et al. Anti-inflammatory effects of anthocyanins from black soybean seed coat on the keratinocytes and ischemia-reperfusion injury in rat skin flaps. Microsurgery. 2012; 32(7): 563-70. [DOI:10.1002/micr.22019] [PMID]

8. Chehelcheraghi F, Eimani H, Sadraie SH, et al. Improved viability of random pattern skin flaps with the use of bone marrow mesenchymal-derived stem cells and chicken embryo extract. Iran J Basic Med Sci. 2015; 18(8): 764-72.

9. Christman S, Kong B, Landry M, Foster D. Chicken embryo extract mitigates growth and morphological changes in a spontaneously immortalized chicken embryo fibroblast cell line. Poult Sci. 2005; 84(9): 1423-31. [DOI:10.1093/ps/84.9.1423] [PMID]

10. Maxwell GD, Reid K, Elefanty A, Bartlett PF, Murphy M. Glial cell line-derived neurotrophic factor promotes the development of adrenergic neurons in mouse neural crest cultures. Proc Natl Acad Sci U SA. 1996; 93(23): 13274-9. [DOI:10.1073/pnas.93.23.13274] [PMID] [PMCID]

11. Hallock GG, Rice DC. Evidence for the efficacy of TRAM flap delay in a rat model. Plastic Reconstruct Surg. 1995; 96(6): 1351-7. [DOI:10.1097/00006534-199511000-00018] [PMID]

12. Liu Y, Dulchavsky DS, Gao X, et al. Wound repair by bone marrow stromal cells through growth factor production. J Surg Res. 2006; 136(2): 336-41. [DOI:10.1016/j.jss.2006.07.037] [PMID]

13. Pikuła M, Langa P, Kosikowska P, Trzonkowski P. Stem cells and growth factors in wound healing. Postepy Hig Med Dosw (On Line). 2015; 69: 874-85. [DOI:10.5604/17322693.1162989]

14. Kwon DS, Gao X, Liu YB, et al. Treatment with bone marrowderived stromal cells accelerates wound healing in diabetic rats. Int Wound J. 2008; 5(3): 453-63. [DOI:10.1111/j.1742481X.2007.00408.x] [PMID] [PMCID]

15. Khorsandi L, Nejad-Dehbashi F, Ahangarpour A, Hashemitabar M Three-dimensional differentiation of bone marrow-derived mesenchymal stem cells into insulin-producing cells. Tissue and cell. 2015; 47(1): 66-72. [DOI:10.1016/j.tice.2014.11.005] [PMID]

16. Karaoz E, Aksoy A, Ayhan S, Sarboyacı AE, Kaymaz F, Kasap M. Characterization of mesenchymal stem cells from rat bone marrow: 
ultrastructural properties, differentiation potential and immunophenotypic markers. Histochem Cell Biol. 2009; 132(5): 533-46. [DOI:10.1007/s00418-009-0629-6] [PMID]

17. Amini A, Pouriran R, Abdollahifar M-A, et al. Stereological and molecular studies on the combined effects of photobiomodulation and human bone marrow mesenchymal stem cell conditioned medium on wound healing in diabetic rats. J Photochem Photobiol. 2018; 182: 42-51. [DOI:10.1016/j.jphotobiol.2018.03.010] [PMID]

18. Babaei S, Ansarihadipour H, Nakhaei M, et al. Effect of Omegaven on mast cell concentration in diabetic wound healing. J Tissue Viability. 2017; 26(2): 125-30. [DOI:10.1016/j.jtv.2016.12.001] [PMID]

19. Im MJ, Kim YS, Edwards RJ, Hoopes JE, Fenselau A. The effect of bovine basic fibroblast growth factor on skin flap survival in rats. Ann Plast Surg. 1992; 28(3): 242-5. [DOI:10.1097/00000637199203000-00007] [PMID]

20. Rodríguez-Lorenzo A, Arufe MC, de la Fuente A, Fernandez F, Blanco F. Influence of flap prefabrication on seeding of subcutaneously injected mesenchymal stem cells in microvascular beds in rats. Ann Plast Surg. 2014; 73(2): 234-8. [DOI:10.1097/SAP.0000000000000074] [PMID]

21. Safayee S, Karbalaei N, Noorafshan A, Nadimi E. Induction of oxidative stress, suppression of glucose-induced insulin release, ATP production, glucokinase activity, and histomorphometric changes in pancreatic islets of hypothyroid rat. Europ J Pharm. 2016; 791: 14756. [DOI:10.1016/j.ejphar.2016.08.024] [PMID]

22. Yang M, Sheng L, Li H, Weng R, Li QF. Improvement of the skin flap survival with the bone marrow-derived mononuclear cells transplantation in a rat model. Microsurgery. 2010; 30(4): 275-81. [DOI:10.1002/micr.20779] [PMID]

23. Byl NN, McKenzie AL, West JM, Whitney JD, Hunt TK, Scheuenstuhl HA. Low-dose ultrasound effects on wound healing: a controlled study with Yucatan pigs. Arch Physic Med Rehabil. 1992; 73(7): 656-64.

24. Babaei S, Bayat M. Effect of pentoxifylline administration on mast cell numbers and degranulation in a diabetic and normoglycemic rat model wound healing. Iran Red Crescent Med J. 2012; 14(7): 48387.
25. Ersel M, Uyanikgil Y, Akarca FK, et al. Effects of silk sericin on incision wound healing in a dorsal skin flap wound healing rat model. Med Sci Monit. 2016; 22: 1064-78. [DOI:10.12659/MSM.897981] [PMID] [PMCID]

26. Chen L, Tredget EE, Wu PY, Wu Y. Paracrine factors of mesenchymal stem cells recruit macrophages and endothelial lineage cells and enhance wound healing. PloS one. 2008; 3(4): e1886. [DOI:10.1371/journal.pone.0001886] [PMID] [PMCID]

27. Huang S, Lu G, Wu Y, et al. Mesenchymal stem cells delivered in a microsphere-based engineered skin contribute to cutaneous wound healing and sweat gland repair. J Dermatol Sci. 2012; 66(1): 29-36. [DOI:10.1016/j.jdermsci.2012.02.002] [PMID]

28. Yu Y, Yao AH, Chen N, et al. Mesenchymal stem cells overexpressing hepatocyte growth factor improve small-for-size liver grafts regeneration. Molec Ther. 2007; 15(7): 1382-9. [DOI:10.1038/sj.mt.6300202] [PMID]

29. Schuleri KH, Amado LC, Boyle AJ, et al. Early improvement in cardiac tissue perfusion due to mesenchymal stem cells. Am J Heart Circulat Physiol. 2008; 294(5): H2002-H11. [DOI:10.1152/ajpheart.00762.2007] [PMID]

30. Bennett S, Griffiths G, Schor A, Leese G, Schor S. Growth factors in the treatment of diabetic foot ulcers. British J Surg. 2003; 90(2): 13346. [DOI:10.1002/bjs.4019] [PMID]

31. Xu PF, Fang MJ, Jin YZ, Wang LS, Lin DS. Effect of oxytocin on the survival of random skin flaps. Oncotarget. 2017; 8(54): 9295565. [DOI:10.18632/oncotarget.21696]

32. Hsueh YY, Wang DH, Huang TC, et al. Novel skin chamber for rat ischemic flap studies in regenerative wound repair. Stem cell Res Ther. 2016; 7(1): 72. [DOI:10.1186/s13287-016-0333-0] [PMID] [PMCID]

33. Castilla DM, Liu ZJ, Tian R, Li Y, Livingstone AS, Velazquez OC A novel autologous cell based therapy to promote diabetic wound healing. Ann Surg. 2012; 256(4): 560-72. [DOI:10.1097/SLA.0b013e31826a9064] [PMID] [PMCID]

\section{How to Cite This Article:}

Rezazadeh K, Chehelcheraghi F, Anbari K. The Effect of Bone Marrow Derived Mesenchymal Stem Cells on the Survival of Random Skin Flap on Sterptozotocin-Induced Diabetic Rats. J Adv Med Biomed Res. 2018; 26 (119) :24-33

\section{Download citation:}

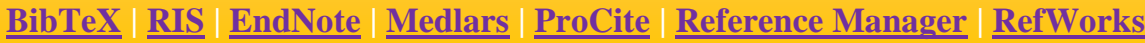

\section{Send citation to:}

\section{(3).}

